\title{
Selection on fruit traits is mediated by the interplay between frugivorous birds, fruit flies, parasitoid wasps and seed- dispersing ants
}

\author{
Facundo X. Palacio ${ }^{1}$ \\ Mariano Ordano ${ }^{1}$
}

\author{
Adam M. Siepielski ${ }^{2}$
}

| Mariela V. Lacoretz ${ }^{3}$

\begin{abstract}
Every organism on Earth must cope with a multitude of species interactions both directly and indirectly throughout its life cycle. However, how selection from multiple species occupying different trophic levels affects diffuse mutualisms has received little attention. As a result, how a given species amalgamates the combined effects of selection from multiple mutualists and antagonists to enhance its own fitness remains little understood. We investigated how multispecies interactions (frugivorous birds, ants, fruit flies and parasitoid wasps) generate selection on fruit traits in a seed dispersal mutualism. We used structural equation models to assess whether seed dispersers (frugivorous birds and ants) exerted phenotypic selection on fruit and seed traits in the spiny hackberry (Celtis ehrenbergiana), a fleshy-fruited tree, and how these selection regimes were influenced by fruit fly infestation and wasp parasitoidism levels. Birds exerted negative correlational selection on the combination of fruit crop size and mean seed weight, favouring either large crops with small seeds or small crops with large seeds. Parasitoids selected plants with higher fruit fly infestation levels, and fruit flies exerted positive directional selection on fruit size, which was positively correlated with seed weight. Therefore, higher parasitoidism indirectly correlated with higher plant fitness through increased bird fruit removal. In addition, ants exerted negative directional selection on mean seed weight. Our results show that strong selection on phenotypic traits may still arise in perceived diffuse species interactions. Overall, we emphasize the need to consider diverse direct and indirect partners to achieve a better understanding of the mechanisms driving phenotypic trait evolution in multispecies interactions.
\end{abstract}

\section{KEYWORDS}

Acromyrmex lundii, Celtis ehrenbergiana, frugivory, plant-animal interactions, Rhagoletotrypeta pastranai, seed dispersal, selection gradients, structural equation model, Utetes anastrephae 


\section{1 | INTRODUCTION}

One unifying goal in evolutionary biology is to understand how interactions between species shape the evolution of their phenotypes and in turn how this mediates species interactions (Agrawal, 2001; Thompson, 1999). However, disentangling how species may alter the evolution of traits of their interacting partners has been challenging, because species typically interact both directly and indirectly through interactions mediated by other species (Ohgushi, Schmitz, \& Holt, 2012; Strauss \& Irwin, 2004; terHorst et al., 2015; Walsh, 2013). Although ecologists have long acknowledged the complexity of species interactions in nature, studies in the evolution of biotic interactions have classically focused on the reductionist view of direct, pairwise interactions (Møller, 2008; Strauss \& Irwin, 2004). Over the last several decades, nevertheless, there has been an increase in studies assessing how multispecies interactions affect both the ecological and evolutionary outcomes of interactions that could have not been achieved by looking at pairwise interactions alone (Beduschi, Tscharntke, \& Scherber, 2015; Craig, Itami, \& Horner, 2007; Siepielski \& Benkman, 2004; Start, Weis, \& Gilbert, 2019).

Like every organism, plants must deal with multiple mutualists and antagonists throughout their life cycle (Lawton, 1999), including herbivores, pathogens, mycorrhizal fungi, parasites, pollinators, seed dispersers and seed predators (Van Dam, 2009). The species involved in these interactions are taxonomically and ontogenetically diverse, use different parts of the plant and vary in their impacts on plant fitness (Strauss \& Irwin, 2004). In turn, each of these species interact with other species that do not directly interact with the plant (e.g. plant-herbivore-parasite or plant-pollinator-predator interactions), resulting in complex interaction networks that can generate cascading effects (Harvey, Van Dam, \& Gols, 2003; Singer, Farkas, Skorik, \& Mooney, 2012; Tscharntke, 1992). However, the influence of other species and other trophic levels on mutualisms has received much less attention than other types of interactions (Bronstein \& Barbosa, 2002; see Strauss \& Irwin, 2004 for a review).
Like most plant structures, fruits and seeds contend with multiple different interactions simultaneously or at different points in their life cycles, which often generate conflicting selection pressures that constrain the evolution of fruit and seed traits. This occurs because plants face trade-offs in attracting seed dispersers while also attracting antagonists, which have been shown to modulate selection on fruit and seed traits (Cazetta, Schaefer, \& Galetti, 2008; Herrera, 1984; Manzur \& Courtney, 1984; Whitney \& Stanton, 2004). For instance, birds often favour large seeds during the dispersal stage in fleshy-fruited plants, but seed size is also often under opposing selection by seed predators (Alcántara \& Rey, 2003; Gómez, 2004, Martínez, García, \& Obeso, 2007). As another example, predispersal seed predators favour increased seed defences in pine species, conflicting with selection exerted by birds for traits that promote seed dispersal (Siepielski \& Benkman, 2007a). These studies have provided valuable knowledge about the effects of different species on shaping phenotypic selection on plant traits, yet how plants amalgamate the combined effects of multiple mutualists and antagonists remains still poorly understood.

Endozoochorous seed dispersal is classically treated as a textbook example of mutualism, in which nutrients in the fleshy pulp (nutrition benefit) are exchanged for seed dispersal services provided by animals (transportation benefit). Nevertheless, this interaction has been shown to be much more complex than previously thought, as the outcomes of the interaction are expected to be influenced by the presence of other species and trophic levels in several ways (Bronstein \& Barbosa, 2002). First, this mutualism may be altered by antagonists of one of the partners. For instance, fruits often attract frugivorous insects interfering with seed dispersal by making plants less attractive to birds (Traveset, Willson, \& Gaither, 1995; Valburg, 1992). Second, seed dispersal may be altered by other mutualists of one of the partners. As an example, plants may attract more seed dispersers when neighbouring plants bear fruit simultaneously, enhancing plant fitness (Guerra et al., 2017; Morales, Rivarola, Amico, \& Carlo, 2012; Sargent, 1990). Third, seed dispersal
FIGURE 1 Spiny hackberry (Celtis ehrenbergiana) and its multiple interactors. (a) spiny hackberry fruits are consumed and dispersed by several frugivorous birds, including (b) rufous-bellied thrush (Turdus rufiventris) and (c) monk parakeet (Myiopsitta monachus); (d) leaf-cutting ants (Acromyrmex lundii) are secondary seed dispersers; (e) the fruit fly Rhagoletotrypeta pastranai oviposits its larvae in the fruit, which are attacked by (f) the parasitoid wasp Utetes anastrephae. Photo credits: F. X. Palacio (a-c), and F. Luque (d). (e) and (f) taken from Palacio, Lacoretz, Pérez, and Ordano (2019)
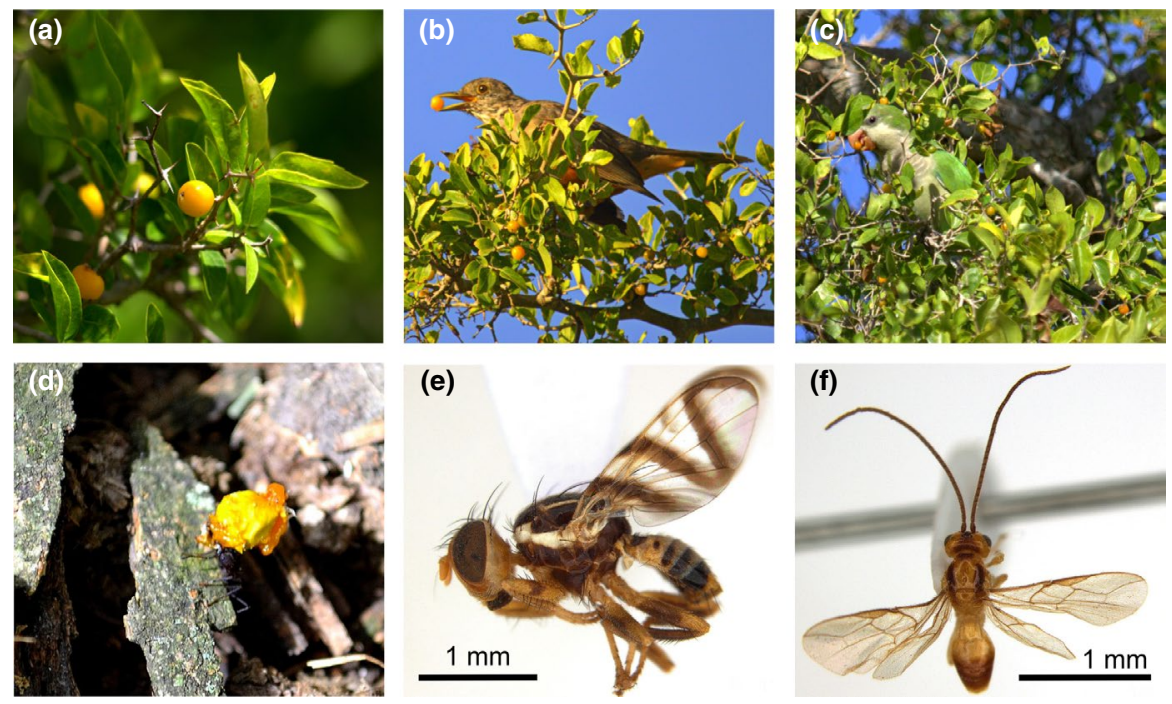
may be altered by exploiters of the mutualism (Bronstein, 2001). For instance, pulp-consuming birds often ingest fruit rewards without dispersing seeds (Schupp, 1993; but see Loayza \& Knight, 2010), or ants may either enhance or decrease seed dispersal depending on dispersal syndrome, plant and ant species characteristics (Penn $\&$ Crist, 2018). These examples of different multispecies and multitrophic interactions unveil some of the complexity in interaction networks, whose ecological and evolutionary influences on the outcome of beneficial pairwise interactions have seldom been addressed.

Therefore, we investigated how multispecies interactions between plants, frugivorous birds, ants, fruit flies and parasitoid wasps shape selection on fruit and seed traits in the spiny hackberry (Celtis ehrenbergiana; Figure 1). To this end, we assessed how phenotypic selection on fruit and seed traits by seed dispersers was influenced by fruit flies and parasitoid wasps (Figure 2). Specifically, we addressed the following questions: (a) Do different mutualistic seed dispersers (birds and ants) exert different selection pressures on fruit and seed traits? And (b) how is selection imposed by dispersers influenced by antagonistic fruit flies and parasitoids? Given the nature of these direct and indirect interactions and the presence of multiple potentially conflicting selection pressures, diffuse selection on fruit and seed traits, as a general outcome, was expected. Thus, we predicted that the impact of different interactors on plant fitness would depend on the presence or absence of other species (Siepielski \& Benkman, 2004; Strauss, Sahli, \& Conner, 2005; Thompson, 2009). More specifically, parasitoids were expected to exert selection on fruit and seed traits similar to that exerted by fruit flies (e.g. if fruit flies select large fruits to oviposit larvae, it is expected that parasitoids also select large fruits, as a by-product of fruit fly selection). Birds, in turn, were expected to select against those fruit and seed traits selected by fruit flies and, indirectly, by parasitoids. Ants were also expected to select fruit and seed traits selected by birds. Overall, multiple interactors are expected to create indirect effects on phenotypic selection on fruit and seed traits, leading to nonadditive and diffuse selection (Strauss et al., 2005; terHorst et al., 2015).

\section{2 | MATERIALS AND METHODS}

\section{1 | Study area}

The study was carried out at 'Estancia San Isidro' $\left(35^{\circ} 09^{\prime} \mathrm{S}, 57^{\circ} 23^{\prime} \mathrm{W}\right)$ located in the Biosphere Reserve 'Parque Costero del Sur', northeastern Buenos Aires province, Argentina. The area is composed of native and alien grasslands, and native forest patches, with nearly 9\% forest cover (Goya, Placci, Arturi, \& Brown, 1992). Forest patch size ranges between 0.02 and 1.77 ha (Palacio, 2016), and dominant native tree species are C. ehrenbergiana, Scutia buxifolia, Jodina rhombifolia and Schinus longifolia (Goya et al., 1992). The climate is wet temperate, with mean minimum and maximum temperatures of 6.0 and $26.0^{\circ} \mathrm{C}$, respectively. Annual mean rainfall is $926 \mathrm{~mm}$, with most precipitation occurring in January and February, but without a noticeable dry season.

\subsection{Natural history of the study system}

Our focal plant is the spiny hackberry C. ehrenbergiana (Cannabaceae)-a thorny andromonoecious tree, found in dry forests and scrubs from the southern United States to central Argentina (Berg \& Dahlberg, 2001). It produces actinomorphic, hermaphroditic or male flowers, $4.0 \mathrm{~mm}$ wide (Romanczuk \& del Pero de Martínez, 1978), and is characterized as an insect- and wind-pollinated self-compatible species (Torretta \& Basilio, 2009). Fruits are one-seeded fleshy drupes, $8.5 \pm 0.6 \mathrm{~mm}$ wide (Palacio, Lacoretz, \& Ordano, 2014; Figure 1a). Fruiting occurs mainly from February to April, and it is one of few species fruiting in the dry months (Murriello, Arturi, \& Brown, 1993). Both fruits and seeds are involved in several mutualistic and antagonistic interactions. Seeds are primarily consumed and dispersed by birds, including Turdus rufiventris, Mimus saturninus, Zonotrichia capensis, Agelaioides badius, Paroaria coronata, Pitangus sulphuratus, Elaenia parvirostris and Icterus pyrrhopterus (Palacio et al., 2014). Birds

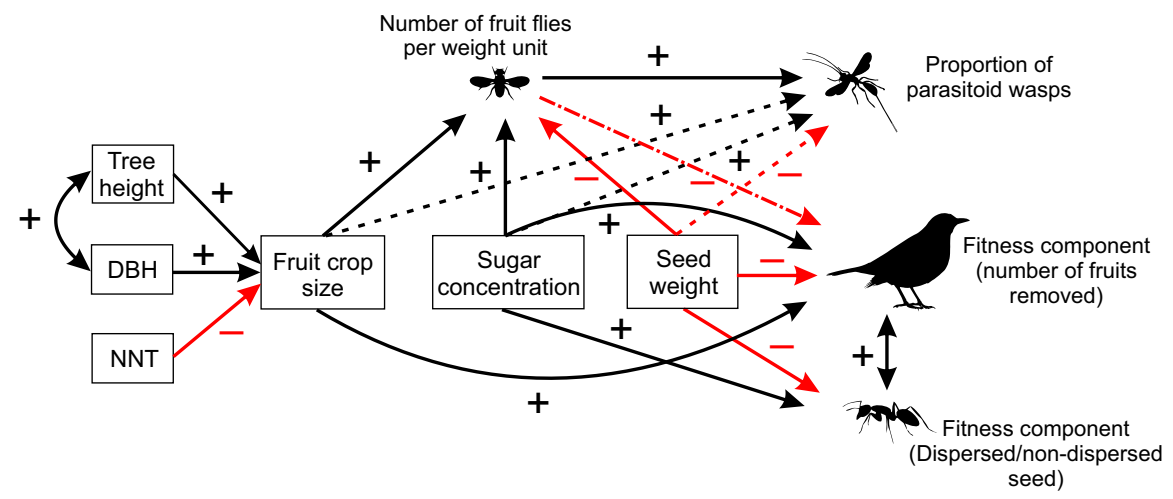

FIGURE 2 Hypothesized causal relationships between plant traits, fruit and seed traits, frugivorous birds, ants, fruit flies and parasitoid wasps. One-headed arrows represent causal relationships between variables, and and the two headed arrow represents a correlation. Signs and colours indicate expected positive (black lines) or negative (red lines) relationships. The full model includes all arrows, whereas Model A includes all arrows except for the dash-dotted arrow, and Model B includes all arrows except for the dashed arrows. DBH: diameter at breast height; NNT: nearest neighbour tree 
either swallow entire fruits or peck the pulp discarding the seeds and the remaining pulp, often in locations suitable for germination (Figure 1b; Palacio et al., 2014).

After seeds reach the ground by primary dispersal or natural fall, they are subject to secondary dispersal by ants (i.e. diplochory; Vander Wall \& Longland, 2004). Although armadillos (Bolković, Caziani, \& Protomastro, 1995) and foxes (Varela, CormenzanaMéndez, Krapovickas, \& Bucher, 2008) also consume spiny hackberry fruits, the latter typically represent a small amount of their diets. One of the main ant seed dispersers at our study site is the native leaf-cutting ant Acromyrmex lundii (Hymenoptera: Formicidae), who are often observed carrying seeds to their nests (Figure 1c) and are considered fungus farmers (Mason et al., 2017; Mehdiabadi \& Schultz, 2010). Interestingly, seeds have no specialized structures to attract ants (elaiosome or other edible appendage attached to the seed), and the reward is presumably represented by the sugary pulp of the fruit (mean sugar concentration $22.5 \pm 3.1^{\circ} \mathrm{Bx}$; Palacio et al., 2014) or by the available biomass for fungus growing (i.e. fruit size). However, information about seed dispersal by ants, as well as their effects on plant establishment survival in the spiny hackberry, remains poorly known. In other systems, nevertheless, ants are known to be important secondary seed dispersers (e.g. Bieber, Silva, \& Oliveira, 2013; Camargo, Rodrigues, Piratelli, Oliveira, \& Christianini, 2019; Christianini \& Oliveira, 2010; Levey \& Byrne, 1993).

In addition, spiny hackberry fruits are attacked by the fruit fly Rhagoletotrypeta pastranai (Diptera: Tephritidae), a specialist on Celtis (Norrbom, 1994; Ovruski, Norrbom, Schliserman, \& Aluja, 2005; Figure 1d). Fruit flies oviposit one egg per fruit inside the fruit pulp, and percentage infestation levels are highly variable ( mean \pm standard deviation $=18.2 \pm 32.1 \%$; Palacio et al., 2019) Only one fruit fly larva is typically found per fruit (only once, a fruit with two larvae out of 2,447 fruits was found; F. X. Palacio unpublished data). In turn, Utetes anastrephae (Hymenoptera: Braconidae) is a generalist koinobiont endoparasitoid (the parasitoid allows the host to continue its development and does not kill the host until the parasitoid larva pupates) ranging from Florida (USA) to Argentina (Sivinski, Aluja, \& López, 1997; Wharton \& Marsh, 1978), which attacks late-instar larvae of R. pastranai (Palacio et al., 2019; Figure 1e). Only one parasitoid is found per fruit fly larvae. Parasitoids emerge after 1-2 months, whereas fruit flies emerge after a 12-months diapause period (Palacio et al., 2019).

\section{3 | Plant, fruit and seed traits}

We mapped all mature trees across 10 forest patches ( $N=80$ trees). For each tree, we measured tree height, diameter at breast height $(\mathrm{DBH})$ and the distance to the nearest reproductive tree (plant traits). We also measured the following fruit and seed traits: total number of ripe fruits per tree (i.e. fruit crop size), sugar concentration and seed weight. In three randomly selected $0.120 \mathrm{~m}^{3}$ cubes within the tree crown, we directly counted the number of ripe fruits (with its characteristic orange-yellow colour; Figure 1a). Fruit crop size was estimated by extrapolating the mean number of ripe fruits per cube to the total tree crown volume. The latter was estimated assuming an ellipsoid, volume $=(4 / 3) \pi a b c$, where $a, b$ and $c$ are the three longest orthogonal semi-axes of the tree crown (Palacio et al., 2014). We collected 10 fruits per tree ( $N=800$ fruits). Pulp and seed fresh weight were measured in the field with an Ohaus scale to the nearest $0.01 \mathrm{~g}$. Total sugar concentration per individual fruit was measured in the field to the nearest $0.25^{\circ} \mathrm{Brix}$ with a Reichert hand-held refractometer $\left(0-50^{\circ} \mathrm{Bx}\right)$. We then computed mean seed weight and mean sugar concentration per tree.

\section{4 | Plant-animal and animal-animal interactions}

At the beginning of the fruiting season, between 24 and 28 February 2014, we randomly selected 56 of the 80 trees. Four branches per tree were tagged, and four other branches were both tagged and enclosed with fine-mesh bags ( $2-\mathrm{mm}$ mesh; $40 \times 30 \mathrm{~cm}$ bags) to prevent bird fruit removal and control for dropped fruits (Ortiz-Pulido, Albores-Barajas, \& Díaz, 2007). On each unbagged branch, we recorded the number of fruits at the beginning of the season $(F b)$ and the number of remaining fruits at the end of the season $(\mathrm{Fe})$, between 28 March and 1 April 2014. On each bagged branch, we recorded the number of fruits at the beginning of the season (Fi) and the number of fallen fruits at the end of the season ( $F f)$. We then computed the mean initial number of fruits for both bagged and unbagged branches at the beginning of the season ( $\mathrm{mFb}$ and $\mathrm{mFi}$ ) and the mean number of remaining fruits at the end of the season $(\mathrm{mFe})$. The mean proportion of fallen fruits per bagged branch (mPFf) was computed as $\mathrm{mpFf}=\mathrm{mFf} / \mathrm{mFi}$ to account for differences in the number of fruits within bagged branches, and the mean number of fallen fruits per unbagged branch $(\mathrm{mFf})$ was estimated as $\mathrm{mFf}=\mathrm{mFi} \times \mathrm{mpFf}$. The expected number of fruits removed per (unbagged) branch $(\mathrm{mFr})$ was then estimated as $\mathrm{mFr}=\mathrm{mFb}-\mathrm{mFe}-\mathrm{mFf}$. The mean proportion of fruits removed per branch ( $m P F r$ ) was computed as $m P F r=m F r / m F i$. Finally, the number of fruits removed per tree $(F r)$ was estimated as the product between fruit crop size ( $F c$, as defined above) and the mean proportion of fruits removed as $F r=F c \times m P F r$. Given that each fruit encloses only one seed, fruit removal equals seed removal. Fruit removal was used as a surrogate for tree fitness (Jordano, 1995; Palacio \& Ordano, 2018; Siepielski \& Benkman, 2007a; Sobral, Guitián, Guitián, \& Larrinaga, 2013) in the context of selection by bird and ants, under the assumption that trees with a higher number of seeds dispersed would have greater potential for dispersal and germination of their seeds (Primack \& Kang, 1989; Siepielski \& Benkman, 2007a, 2008a; see Section 4). Although the proportion of fruits removed may be a better surrogate of fitness for plants whose reproductive output is size-dependent (Jordano, 1995; Siepielski \& Benkman, 2007b; but see Palacio \& Ordano, 2018), we used the number of fruits removed as a fitness component because tree size and fruit crop size were included as covariates in the statistical models (see below) 
In addition, we used ant seed removal as another tree fitness component. Since it is unknown whether ants choose spiny hackberry seeds over fruits, we first carried out a cafeteria experiment in the field between 28 February and 01 March 2014. Cafeteria experiments analyse consumption of food items when offered simultaneously and allow for food preferences to be assessed (Krebs, 1989). We collected 12 fruits per tree from 54 trees ( $N=648$ fruits) and randomly allocated each fruit to one of three treatments simulating the three most common conditions in which fruits and seeds are encountered on the ground (Bieber et al., 2013): intact fruits (no marks or holes of any kind), fruits with the pulp partially removed (approx. a half of fruit volume using a jackknife simulating the mark left by pulp consumers) and clean seeds (pulp manually removed with a jackknife and a paper towel to mimic fruit passage). The three treatments were placed in three random corners of a white cardboard sheet $(10 \times 10 \mathrm{~cm})$ on the leaf litter under each tree. Each treatment received four fruits or seeds. We set the experiment at 08:00 hr and recorded the number of fruits or seeds removed after $10 \mathrm{hr}$, which was a sufficient period of time for seed removal. After checking the sheets, we also visually searched for the presence of ants carrying seeds within a 1-m radius. Because the experiment was carried out under natural conditions, we did not control for the number of ants per replicate. However, we here simply assume that ant seed dispersal increases plant fitness by dispersing seeds away from the mother plant and reducing both predation and fungal attack on ripe fruits that fall on the ground (Janzen, 1970; Connell, 1971; Andersen, 1988; Oliveira, Galetti, Pedroni, \& Morellato, 1995; Giladi, 2006).

To measure fly infestation levels and the proportion of parasitoids per tree, we sampled 70 of the 80 trees between 28 March and 01 April 2014. To this end, we collected 4-20 fruits per tree ( $N=950$ fruits) and reared fruit flies and parasitoids in the laboratory. Fruit samples of the same tree were placed in closed styrofoam vessels (750 cc) with a mesh at the top and damp sand (50 g, 5-10 water drops) in the bottom as a pupation substrate under natural conditions, as detailed in Palacio et al. (2019). One vessel per sampled tree was used (i.e. 70 vessels). For each sampled tree, we measured mean fruit weight with an Ohaus scale to the nearest $0.01 \mathrm{~g}$. Fruit infestation levels and parasitism values were quantified as the number of pupae per $100 \mathrm{~g}$ of fruit (100 g 295 fruits) and the proportion of emerged parasitoids relative to the number of pupae per tree, respectively. We quantified fruit fly infestation levels as the number of pupae per weight unit, because infestation is fruit size-dependent (reviewed by A. Benavidez et al. unpublished manuscript). Moreover, the number of pupae per $100 \mathrm{~g}$ of fruit was strongly correlated with the proportion of pupae per tree $(r=.93, N=70, p<.0001)$.

\section{5 | Data analysis}

To analyse whether ants preferred seeds over fruits in experimental trials, we fitted a generalized linear mixed model (GLMM; Harrison et al., 2018) using the three fruit/seed treatments as the explanatory variable and fruit/seed removal as the response variable. The patch and the sheet nested within the patch were included as random effects. We used a binomial error distribution (number of fruits/seeds removed relative to the total number of diaspores) and a logit-link function.

The relationships between fruit fly infestation and mean fruit weight, and between the proportion of parasitoids and mean fruit weight were assessed using GLMMs with a Gaussian error structure (identity link function) and binomial error structure (logit-link function), respectively. Patch identity was included as a random effect.

To estimate the regime and strength of phenotypic selection on fruit and seed traits, as well as direct and indirect effects of fruit flies and parasitoids on plant fitness, we used piecewise structural equation models (SEM; Scheiner, Mitchell, \& Callahan, 2000; Shipley, 2009). A SEM combines multiple predictor and response variables into a single framework; it is built a priori based on biological knowledge and allows for testing complex direct and indirect relationships between variables (Grace, 2006; e.g. Figure 2). A piecewise SEM allows fitting different error distributions and nonindependent observations, and, since each causal relationship is solved separately, it may fit smaller datasets compared to a traditional SEM (Lefcheck, 2016). Individual relative fitness components (bird fruit and ant seed removal) were estimated as each individual fitness measure divided by its population mean fitness, and traits were standardized to a mean of 0 and a variance of 1 prior to analyses. Therefore, the standardized path coefficients are vectors of partial regression coefficients and thus equivalent to selection gradients comparable among traits and populations (Scheiner et al., 2000; Wood \& Brodie, 2016). Although the effect of increased seed dispersal on survival and establishment is unknown in our study system, we assumed that a higher dispersal delivery increased the probability for a seed to reach a suitable site and thus the probability of seed survival and seedling recruitment (Jordano \& Herrera, 1995; Primack \& Kang, 1989; Siepielski \& Benkman, 2008a). We included forest patch identity as a random effect.

We developed three competing a priori hypotheses based on our understanding of the relationships between plants, fruit and seed traits, seed removal, fruit infestation and parasitoids (Figure 2). The initial full SEM hypothesized that both birds (Palacio et al., 2014; Palacio \& Ordano, 2018; Siepielski \& Benkman, 2007a) and ants (Alcántara et al., 2007; Manzaneda, Rey, \& Alcántara, 2009) act as agents of selection on fruit and seed traits, so we connected the two fruit traits (fruit crop size and mean sugar concentration) and mean seed size to bird fruit removal, and mean sugar concentration and mean seed size to ant seed removal (Figure 2). The number of fruits produced is often a function of plant size and neighbour density (Minor \& Kobe, 2019), so we included a path connecting tree height, $\mathrm{DBH}$ and the distance to the nearest neighbour to fruit crop size, as well as a correlation between tree height and DBH. Fruit flies are highly selective of fruit traits, such as fruit crop size, fruit colour, size and shape, because these are critical for oviposition and larva survival (Jordano, 1987; Poyet et al., 2015; Prokopy, 1968; Prokopy, Cooley, \& Papaj, 1993). We therefore included paths connecting fruit and seed traits to infestation levels (Figure 2). In turn, birds may 
also respond to fruit infestation by rejecting low attractive or unhealthy fruits (García, Zamora, Gómez, \& Hódar, 1999; Janzen, 1977; Valburg, 1992), so we included a path between fruit infestation and bird fruit removal. Parasitoids are highly specialized predators, which rely on chemical, visual and mechanical cues to find their hosts (Godfray, 1994; Wajnberg, Bernstein, \& Van Alphen, 2008). We thus included paths from fruit traits and fruit infestation to the proportion of parasitoids per plant (Figure 2). Finally, we added a correlation between both fitness components. Shipley's tests of directed separation were used to test the assumption that there are no missing relationships among unconnected variables (Shipley, 2009).

The initial full SEM was compared to a set of two alternative nested models built by constraining some paths to zero. Model A considered that birds find it difficult to discriminate against infested fruits. Thus, we removed the path between fruit infestation and bird fruit removal. Model B hypothesized that the proportion of parasitoids is mainly driven by infestation levels rather than by fruit and seed traits. Thereby, we removed those paths from fruit and seed traits to the proportion of parasitoids. Significant standardized linear paths indicate that selection favours either a phenotypic mean increase (if positive) or decrease (if negative). Significant standardized nonlinear paths indicate nonlinear selection against extreme phenotypes (stabilizing selection), nonlinear selection against intermediate trait values (disruptive selection) or correlational selection on a given trait combination (Lande \& Arnold, 1983; Scheiner et al., 2000). Given that fruit crop size showed a right-skewed distribution, we fitted a SEM with only linear terms and a SEM with linear, quadratic and cross-product (interaction) terms for each hypothesis to obtain unbiased estimates of linear and nonlinear selection, respectively (Scheiner et al., 2000). This is because the full model (with linear, quadratic and interaction terms) gives biased linear selection coefficients, unless phenotypic traits meet multivariate normality (Lande \& Arnold, 1983). Correlations between a given trait and its square were also included (Scheiner et al., 2000). Given that quadratic selection is a necessary, but not sufficient, condition to infer stabilizing or disruptive selection (Phillips \& Arnold, 1989), we visually inspected plots between fruit traits and fitness when a significant quadratic path was found. The strength of indirect effects was computed as the product between coefficients of direct effects along a given path (Grace, 2006).

Due to the particular landscape structure of our study area, that is, small forest patches immersed in a grassland matrix, a patch effect on natural selection patterns is expected. That is, selection is expected to be more similar within than between patches. Although we cannot be certain of the factors accounting for this variation, this patch effect can illustrate the importance of latent environmental factors underlying how selection operates under specific spatial contexts and scales. We therefore quantified the proportion of variance explained by the fixed effects only and the combined fixed and random effects as the marginal $R^{2}{ }_{\text {GLMM }}$ and the conditional $R_{\text {GLMM }}^{2}$, respectively, following Nakagawa, Johnson, and Schielzeth (2017). Both linear and quadratic models were compared using Akaike's information criterion corrected for small sample sizes

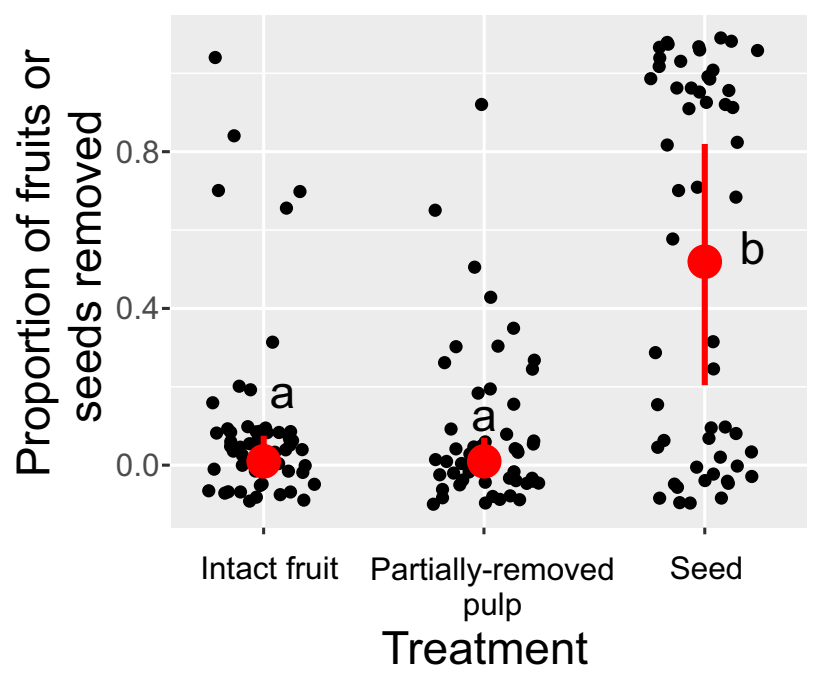

FIGURE 3 Results of cafeteria experiments (control [intact fruit], partially removed pulp and seed) on ant fruit/seed removal. Red points and lines depict estimates and 95\% confidence intervals of a generalized linear mixed model (see Section 2). Jittered points (individual seeds/fruits) are also shown. Different letters indicate statistically significant differences $(p<.05)$ between treatments

(AICc; Shipley, 2013). Best linear and nonlinear models were evaluated using Shipley's test of directed separation, which yields Fisher's $C$ statistic that can be compared with a chi-square distribution (Shipley, 2009). Model fit is considered poor when Fisher's $C$ has a $p<.05$ (Shipley, 2009). To visualize the shape of fitness surfaces, we used nonparametric cubic splines (one trait) and thin-plate splines (two traits; Morrissey \& Sakrejda, 2013).

All graphs and analyses were performed in R 3.5.2 ( $\mathrm{R}$ Core Team, 2018) using the packages Ime4 (Bates, Maechler, Bolker, \& Walker, 2015), piecewiseSEM (Lefcheck, 2016), nlme (Pinheiro, Bates, DebRoy, \& Sarkar, 2018), mgcv (Wood, 2017), fields (Nychka, Furrer, Paige, \& Sain, 2017) and ggplot2 (Wickham, 2016).

\section{3 | RESULTS}

The cafeteria experiment showed significant differences between treatments (GLMM: $F_{2,157}=63.05, p<.0001$ ). In particular, ants removed almost six times more seeds than fruits, whereas no differences in removal between intact and partially removed pulp fruits were detected (mean proportion of intact fruits removed $=0.09 \pm 0.24$, mean proportion of fruits with the pulp partially removed $=0.09 \pm 0.21$, mean proportion of seeds removed $=0.53 \pm 0.47$; Figure 3 ). Overall, the model accounting for both fixed and random effects explained more than $80 \%$ of the variation in ant seed/fruit removal (conditional $R_{\text {GLMM }}^{2}=.82$ vs. marginal $R_{\text {GLMM }}^{2}=.26$ ), indicating a strong patch effect on ant seed dispersal.

Fruit fly infestation was relatively low (mean $=29.85$ pupae $/ 100 \mathrm{~g}$, standard deviation $=39.28$ pupae $/ 100 \mathrm{~g}$, mean percentage infestation level $=12.86 \%$, standard deviation $=14.56 \%$, $N=70$ ). The proportion of parasitoids per tree was also relatively 
low $(18.00 \%$, standard deviation $=31.98 \%, N=70)$. Rearing experiments showed that both fruit fly infestation (GLMM: $F_{1,67}=13.38$, marginal $R_{\text {GLMM }}^{2}=.030$, conditional $R^{2}{ }_{\mathrm{GLMM}}=.059, p=.0002$, estimate $\pm S E=4.54 \pm 1.24$ ) and the proportion of parasitoids (GLMM: $F_{1,67}=4.32$, marginal $R_{\text {GLMM }}^{2}=.034$, conditional $R_{\text {GLMM }}^{2}=.034$, $p=.037$, estimate $\pm S E=4.80 \pm 2.31$ ) per plant were positively related to mean fruit weight.

Both the linear and nonlinear Model B were the best models and had good fit to the data (Table 1), and no missing paths were statistically significant (all $p$ 's $>$.05). Moreover, the inclusion of a random component accounting for patch identity increased explained variation in infestation levels and ant seed removal (conditional $R_{\text {GLMM }}^{2}=.09$ and 0.31 vs. marginal $R_{\text {GLMM }}^{2}=.01$ and 0.11 , respectively), indicating a patch effect on these response variables. Both models showed that $\mathrm{DBH}$ and tree height were positively correlated (path coefficient $=0.466, p<.0001$ ), and these positively affected fruit crop size (DBH path coefficient $\pm S E=0.288 \pm 0.114$, $p=.014$, tree height path coefficient $\pm S E=0.243 \pm 0.115, p=.038$; Figure $4 a)$. Birds exerted positive directional selection on fruit crop size (path coefficient $\pm S E=0.686 \pm 0.288, p=.022$ ), indicating that tree size (height and DBH) was also indirectly selected by birds (indirect $\mathrm{DBH}$ path coefficient $=0.198$, indirect tree height path coefficient $=0.167)$. Both SEMs A and B indicated that the proportion of parasitoids was positively determined by fruit infestation levels (path coefficient $\pm S E=0.266 \pm 0.118, p=.028$; Figure 4). By contrast, fruit and seed traits did not account for variation in fruit infestation or parasitoidism levels.

Ants exerted directional selection against mean seed weight (path coefficient $\pm S E=-0.226 \pm 0.105, p=.038$; Figure 4a). In addition, Model $B$ also showed that birds exerted negative correlational selection on the combination of fruit crop size and seed weight (path coefficient $\pm S E=-1.047 \pm 0.414, p=.016$; Figure $4 b$ ), favouring either large crops with small seeds or small crops with large seeds (Figure 5a). Therefore, plants with large crops and small seeds were favoured by both seed dispersers, but those plants with small crops were only favoured by birds if they had large seeds, presumably due to a positive correlation between seed and pulp weight $(r=.40, N=800$, $p<.0001$ ). When looking at total (direct and indirect) phenotypic

TABLE 1 Comparison of piecewise structural equation fits for both linear and nonlinear models

\begin{tabular}{|llllllr|} 
Model & Fisher's $C$ & $d f$ & $p$ & AICc & $\kappa$ & $\Delta$ AICc \\
\hline Full linear & 42.95 & 36 & .198 & 270.9 & 30 & 60.5 \\
\hline A linear & 41.35 & 38 & .326 & 228.9 & 29 & 18.5 \\
\hline B linear & 45.23 & 42 & .339 & 210.4 & 27 & 0.0 \\
\hline $\begin{array}{l}\text { Full } \\
\quad \text { quadratic }\end{array}$ & 49.77 & 52 & .562 & 720.9 & 40 & 288.5 \\
\hline A quadratic & 52.98 & 56 & .590 & 534.0 & 39 & 101.6 \\
\hline B quadratic & 58.54 & 60 & .529 & 432.4 & 36 & 0.0 \\
\hline
\end{tabular}

Abbreviations: AICc, Akaike's information criterion corrected for small sample sizes; $d f$, degrees of freedom; $K$, number of parameters; $\triangle \mathrm{AICc}$, difference between $\mathrm{AICc}$ of the candidate model and the lowest $\mathrm{AICc}$ value among all models being compared. selection on seed weight, selection exerted by birds and ants was conflicting (Figure $5 b$ ). Summaries of best linear and quadratic model coefficients are available as Tables S1 and S2, respectively.

\section{4 | DISCUSSION}

\subsection{The diffuse nature of selection mediated by multiple species}

Our results show that multispecies interactions represent complex systems and that both direct and indirect effects play significant roles in generating phenotypic selection on fruit and seed traits. Birds exerted negative correlational selection on the combination of fruit crop size and mean seed weight, favouring either large crops with small seeds or small crops with large seeds. In turn, ants exerted negative directional selection on mean seed weight. This suggests that the impact of ant-mediated selection on plant fitness depends on bird-mediated selection, resulting in diffuse selection (Strauss \& Irwin, 2004; Strauss et al., 2005). In particular, one scenario (large crops-small seeds) favoured diplochory by enhancing plant fitness, whereas another (small crops-large seeds) led to disruptive selection on seed size. In addition, parasitoids selected plants with higher fruit fly infestation levels, and fruit flies positively selected mean fruit size, which positively correlated with mean seed weight. Therefore, higher parasitoidism indirectly led to higher plant fitness through increased seed dispersal, despite birds not responding to fruit fly infestation (e.g. no path between fruit fly and birds). This suggests either that fruit fly infestation levels are too low to affect bird consumption behaviour or that birds may not discriminate between infested and noninfested fruits. The latter is supported by the observation that no external damage by fruit flies is evident at least by human visual perception. Overall, any adaptive evolutionary responses to selection imposed from the rich community of interacting species on this single species likely represent the combined effects of multifarious selection.

\section{2 | Bird- and ant-mediated selection on fruit and seed traits}

The fitness surface of bird-mediated selection showed two peaks: (a) small fruit crop sizes with large seeds and (b) large fruit crop sizes with small seeds. Both peaks could be the result of different selection regimes exerted by a diverse frugivorous bird assemblage, whose species vary in morphology (e.g. gape limitation), fruit-eating behaviour and foraging preference (Palacio, Girini, \& Ordano, 2017; Palacio et al., 2014). In other words, birds are expected to select optimal fruit trait combinations, rather than isolated traits (Palacio, Girini, et al., 2017; Sobral, Larrinaga, \& Guitián, 2010). In particular, the first trait combination would be selected by pulp consumers who only peck the pulp, for which seed size does not represent an energetic cost (Levey, 1987; Palacio, Valoy, et al., 2017). Although this fruit-handling 


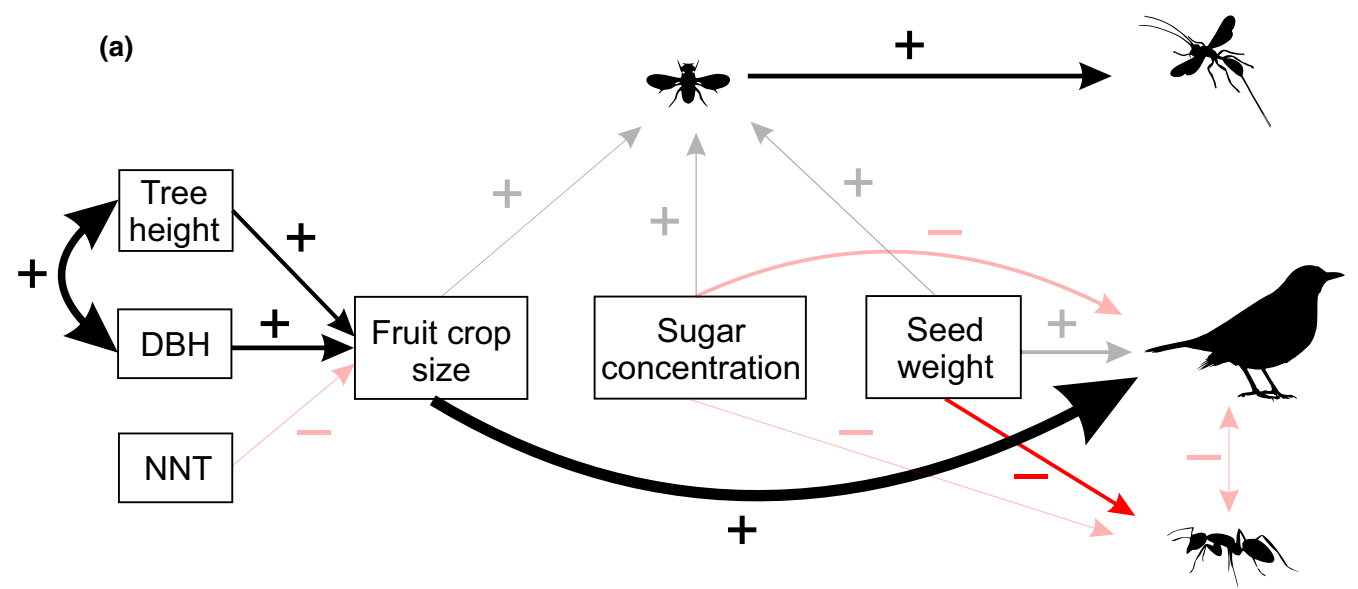

(b)

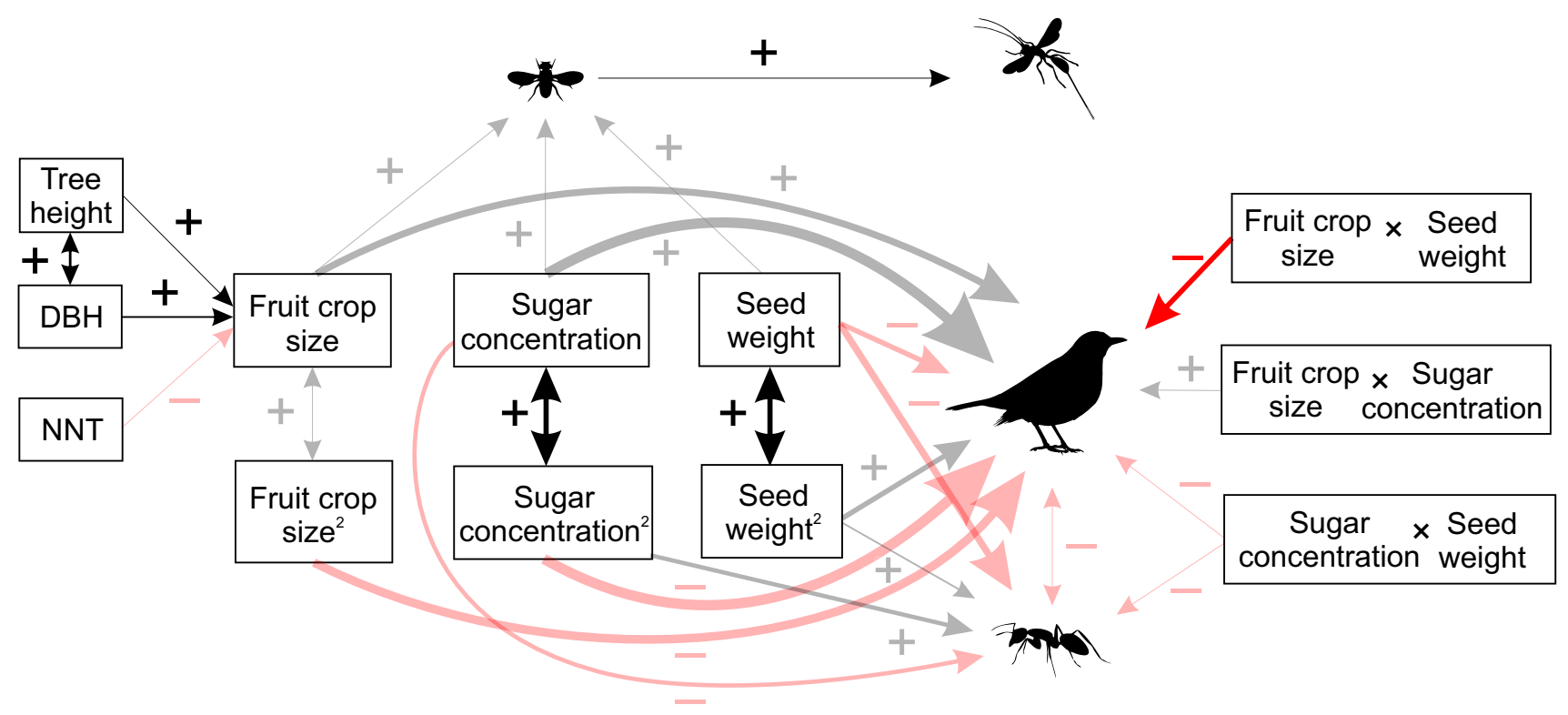

FIGURE 4 Best piecewise structural equation (SEM) models for the relationships between tree size, neighbour density, fruit and seed traits, bird fruit removal, ant seed removal, fruit fly infestation and proportion of parasitoids (black silhouettes). (a) Best linear SEM model (Table S1) and (b) best nonlinear SEM model (Table S2) are shown. The width of the arrow is proportional to the path (one-headed arrows) or correlation coefficient (two-headed arrows). Black and red indicate positive and negatively relationships, respectively, whereas solid and transparent colours depict significant and nonsignificant paths, respectively. Signs indicate positive (+) or negative (-) relationships. DBH: diameter at breast height; NNT: nearest neighbour trees

behaviour is expected to have detrimental effects on seed recruitment, secondary dispersal by ants would relax this effect by dispersing fallen seeds. As our experiments showed, ants removed almost six times more seeds than either intact or pecked fruits, which supports the hypothesis that ants can act as seed dispersers. Moreover, ants exerted negative directional selection on seed size. This was expected, as body size constrains seed dispersal distances in ants (Gómez \& Espadaler, 2013; Ness, Bronstein, Andersen, \& Holland, 2004). The complementary seed dispersal ants provide seems to be particularly relevant in some fleshy-fruited plants, in which diplochory allowed seed removal of up to $83 \%$ of fallen diaspores in Xylopia aromatica (Christianini \& Oliveira, 2010) and a 42\% increase in seed dispersal effectiveness in Erythroxylum ambiguum compared to dispersal by birds alone (Camargo et al., 2019). Our results (53\% of seeds removed) fall within this range and highlight the potential and overlooked impact ants may have on seed dispersal. It should be noted that ants can act not only as mutualists, but also as antagonists by eating harvested seeds (Levey \& Byrne, 1993; Penn \& Crist, 2018). Moreover, seed germination on ant nests can be lower than that on the surrounding-site soil (Varela \& Perera, 2003). Therefore, further studies are needed to assess the impacts of ant-mediated dispersal on seed removal, establishment and viability (Giladi, 2006).

On the other hand, the large crops-small seeds combination would be favoured by gulpers who swallow fruits whole, for which seed size is expected to be selected against (Levey, 1987; Palacio, Valoy, et al., 2017). As a result, ants would provide a redundant seed 

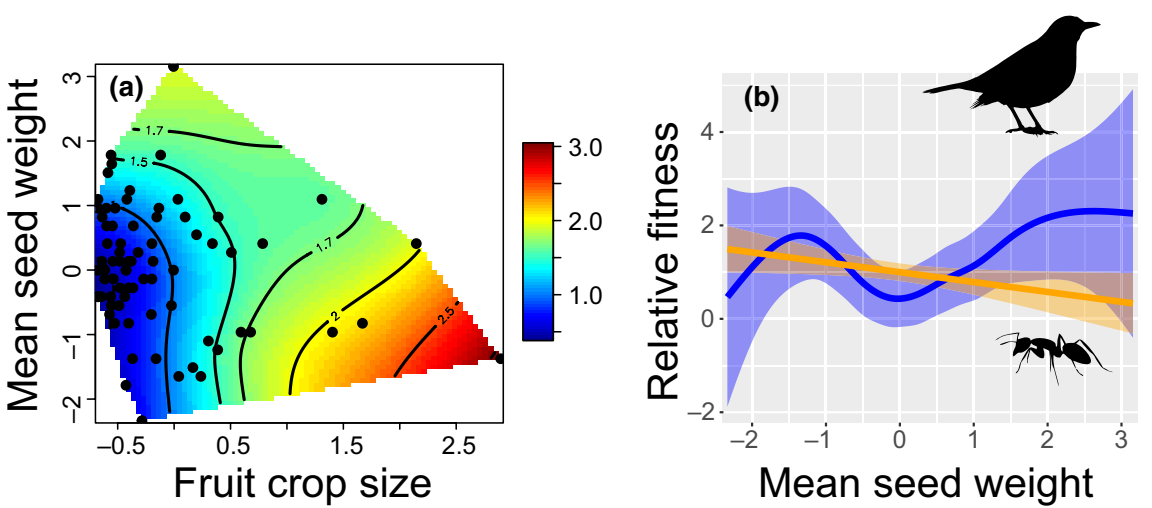

FIGURE 5 Bird- and ant-mediated phenotypic selection on fruit display traits. (a) Response surface (thin-plate splines) showing birdmediated correlational selection between standardized fruit crop size and mean seed size. Black circles represent individual trees. Lines and scale bars depict predicted relative fitness. (b) Conflicting selection exerted by birds (blue line) and ants (orange line) on mean seed weight. Contour lines and bands depicting predictions and 95\% confidence intervals from cubic splines are shown

dispersal delivery, enhancing plant fitness. In this sense, dispersed seeds are slightly but significantly heavier (around $8.5 \%$ ) than nondispersed seeds in this population (Palacio et al., 2014), suggesting that large seeds are favoured by overall selection, but to such an extent of barely outweighing other counteracting selection pressures. Both trait combinations under selection suggest a trade-off between fruit number and size and that seed dispersers may shape the evolution of seed size and number. Moreover, fruit crop size is a highly heritable trait in fleshy-fruited plants (broad-sense heritability $=83.0 \%$ 99.0\%; see Palacio \& Ordano, 2018 and references therein) which, coupled to a strong phenotypic selection, suggests a strong response to selection. Small seeds would presumably experience low dispersal probability, but also low predation (Martínez et al., 2007). By contrast, large seeds will presumably experience high dispersal probability, but then will be selected against by post-dispersal seed predation, leading to stabilizing selection (Martínez et al., 2007; Gómez, 2004). The spiny hackberry is an interesting system to study from this perspective, because it produces only one seed per fruit, allowing to tease apart the effect of seed number within fruits on the size-number trade-off. Thus, fruit crop size equals the total number of seeds produced, and a negative correlation between fruit crop and seed size is expected. Interestingly, we found no plants with relatively large crops and large seeds (see Figure $5 \mathrm{a}$ ), suggesting a potential trade-off between seed size and number. However, a nonsignificant negative effect size between fruit crop and mean seed size was found ( $r=-.15, N=80, p=.17$ ), suggesting that other factors, such as plant size, age, climate and resource availability, correlate with seed size (Jakobsson \& Eriksson, 2000; Wulff, 1986).

\section{3 | Seed removal as an early-stage fitness component}

The main limitation of our study is that we have only quantified two fitness components at an early plant life stage: fruit removal by birds and seed removal by ants. As in many studies of long-lived plants, fruit and seed removal have been largely used as fitness components in the context of animal-mediated selection (Fontúrbel \& Medel, 2017; Jordano, 1995; Martínez et al., 2007; Palacio et al., 2014; Siepielski \& Benkman, 2007a, 2008b; Sobral et al., 2013), under the assumption that increased seed delivery increases the probability of reaching suitable conditions, and thus seed survival and recruitment (Jordano \& Herrera, 1995; Primack \& Kang, 1989; Siepielski \& Benkman, 2008a). Nevertheless, growing evidence shows that conflicting selection may act on post-dispersal stages of recruitment. For instance, Alcántara and Rey (2003) found that small seeds of Olea europaea (Oleaceae) had higher bird-mediated dispersal probabilities, but after dispersal, large seeds had higher survival probabilities. In other two studies, Gómez (2004) and Martínez et al. (2007) found that large seeds of Quercus ilex (Fagaceae) and Crataegus monogyna (Rosaceae), respectively, had higher dispersal probabilities, but large seeds had higher post-dispersal predation probabilities and thus lower survival probabilities. Despite the presence of conflicting selection, the cumulative effects of selection may still be significant as selection acting through one fitness component can influence the distribution of phenotypic traits during subsequent bouts of selection (Jordano \& Herrera, 1995; Martínez et al., 2007). An appropriate analysis of plant fitness would require knowledge of the multiple sequential dispersal stages involved in the plant life cycle (Wang \& Smith, 2002), yet achieving this would be extremely challenging for long-lived trees and indeed we are not aware of any study quantifying animal-mediated selection on fruit and seed traits using fitness components from seed removal to adult plant recruitment (but see Siepielski \& Benkman, 2008a). To our knowledge, most studies have analysed between two and four fitness components (e.g. Fontúrbel \& Medel, 2017; Gómez, 2004; Martínez et al., 2007) and rarely up to six (Alcántara \& Rey, 2003).

\subsection{Strong selection pressures may exist in diffuse interactions}

There is a long-held notion that multispecies assemblages of seed dispersers prevent reciprocal adaptation between plants and 
seed dispersers, leading to diffuse co-evolution (Herrera, 1985; Tewksbury, 2002; Wheelwright \& Orians, 1982). One of the arguments to support this statement is that frugivores exert low and inconsistent selection pressures on fruit traits, because many potential selective agents coexist (Herrera, 1985; Wheelwright \& Orians, 1982). Nevertheless, growing evidence has shown that seeddispersing animals may exert strong and consistent selection pressures on fruit and seed traits (Jordano, 1995; Martínez et al., 2007; Palacio \& Ordano, 2018; Sobral et al., 2013). It should be noted that we have no data on traits under selection on seed dispersers (e.g. bird bill traits or ant body size), and we have only estimates of selection imposed by each agent, not evolutionary responses. Moreover, we still lack studies addressing the potential for temporal and spatial variation in selection on fruit crop size as well. Yet, selection on the latter trait could vary spatially (e.g. high variation in fruit crop size among populations) and temporally (e.g. absence of selection during very small fruit crop years), both of which could affect the opportunity for selection. Indeed, selection can be strong and drive trait evolution only during infrequent years of large seed production (Siepielski \& Benkman, 2007b). Although we quantified phenotypic selection in only one episode, our results show that strong selection pressures on fruit traits may be exerted by seed dispersers in the presence of multiple interactions. What remains unknown is how these varying selection pressures generate differences in adaptive evolution across the landscape.

A second constraint argued for reciprocal adaptation between plants and seed dispersers is that antagonist-mediated selection relaxes total selection exerted on fruit and seed in post-dispersal stages, favouring diffuse co-evolution (Herrera, 1985; Wheelwright $\&$ Orians, 1982). For instance, several studies have found that large seeds are more likely to be dispersed or established, but also to be attacked by seed predators (Alcántara \& Rey, 2003; Gómez, 2004; Manzaneda et al., 2009; Siepielski \& Benkman, 2007a). Even in the presence of conflicting selection, however, total selection may be still significant (Martínez et al., 2007), increasing phenotypic trait variation at the population level (Siepielski \& Benkman, 2010). In the spiny hackberry, ants exerted conflicting selection on seed size imposed by birds in one partial selective scenario. Regardless of the categorical label put to interactors participating in the system (mutualist or antagonist), our results show that counteracting selective pressures on plant traits arise from interspecific differences in scaling effects, behaviour and foraging preferences on fruit traits (Morales, García, Martínez, Rodriguez-Pérez, \& Herrera, 2013; Peters, Oberrath, \& Böhning-Gaese, 2003). Overall, our results suggest that strong selection on traits may still arise, even in what are often perceived as diffuse species interactions, highlighting the evolutionary potential of phenotypic trait variation in multispecies interactions.

\section{ACKNOWLEDGMENTS}

We thank Douglas Earnshaw for logistical support. Facundo Quintela, Bárbara Malagisi, Jorgelina Villanova and Carolina Bruzzese provided field assistance. Elián Guerrero identified the specimens of
Acromyrmex lundii. Facundo Luque provided a photograph of $A$. lundii. Two anonymous reviewers greatly improved an early version of the manuscript. Consejo Nacional de Investigaciones Científicas y Técnicas (MINCyT) and Fundación Miguel Lillo (Projects Z-0048-1 and Z-0113-1) provided partial funding.

\section{DATA AVAILABILITY STATEMENT}

The dataset "Data from: Selection on fruit traits is mediated by the interplay between frugivorous birds, fruit flies, parasitoid wasps, and seed-dispersing ants" has been approved for publication in Dryad. Data https://doi.org/10.5061/dryad.gxd2547hn

\section{ORCID}

Facundo X. Palacio (iD https://orcid.org/0000-0002-6536-1400

Adam M. Siepielski iD https://orcid.org/0000-0002-9864-743X

Mariela V. Lacoretz iD https://orcid.org/0000-0003-1323-3631

Mariano Ordano (iD https://orcid.org/0000-0003-0962-973X

\section{REFERENCES}

Agrawal, A. A. (2001). Phenotypic plasticity in the interactions and evolution of species. Science, 294, 321-326. https://doi.org/10.1126/ science.1060701

Alcántara, J. M., \& Rey, P. J. (2003). Conflicting selection pressures on seed size: Evolutionary ecology of fruit size in a bird-dispersed tree, Olea europaea. Journal of Evolutionary Biology, 16, 1168-1176. https:// doi.org/10.1046/j.1420-9101.2003.00618.x

Alcántara, J. M., Rey, P. J., Manzaneda, A. J., Boulay, R., Ramírez, J. M., \& Fedriani, J. M. (2007). Geographic variation in the adaptive landscape for seed size at dispersal in the myrmecochorous Helleborus foetidus. Evolutionary Ecology, 21, 411-430. https://doi. org/10.1111/j.1365-2745.2007.01293.x

Andersen, A. N. (1988). Dispersal distance as a benefit of myrmecochory. Oecologia, 75, 507-511. https://doi.org/10.1007/BF00776412

Bates, D., Maechler, M., Bolker, B., \& Walker, S. (2015). Fitting linear mixed-effects models using Ime4. Journal of Statistical Software, 67, 1-48. https://doi.org/10.18637/jss.v067.i01

Beduschi, T., Tscharntke, T., \& Scherber, C. (2015). Using multi-level generalized path analysis to understand herbivore and parasitoid dynamics in changing landscapes. Landscape Ecology, 30, 1975-1986. https://doi.org/10.1007/s10980-015-0224-2

Berg, C. C., \& Dahlberg, S. V. (2001). A revision of Celtis subg. Mertensia (Ulmaceae). Brittonia, 53, 66-81. https://doi.org/10.1007/BF028 05398

Bieber, A. G. D., Silva, P. S., \& Oliveira, P. S. (2013). Attractiveness of fallen fleshy fruits to ants depends on previous handling by frugivores. Ecoscience, 20, 85-89. https://doi.org/10.2980/20-1-3573

Bolković, M. L., Caziani, S. M., \& Protomastro, J. J. (1995). Food habits of the three-banded armadillo (Xenarthra: Dasypodidae) in the dry Chaco, Argentina. Journal of Mammalogy, 76, 1199-1204. https://doi. org/10.2307/1382612

Bronstein, J. L. (2001). The exploitation of mutualisms. Ecology Letters, 4, 277-287. https://doi.org/10.1046/j.1461-0248.2001.00218.x

Bronstein, J. L., \& Barbosa, P. (2002). Multitrophic/multispecies mutualistic interactions: the role of non-mutualists in shaping and mediating mutualisms. In T. Tscharntke, \& B. A. Hawkins (Eds.), Multitrophic level interactions (1st ed., pp. 44-65). Cambridge, UK: Cambridge University Press.

Camargo, P. H., Rodrigues, S. B., Piratelli, A. J., Oliveira, P. S., \& Christianini, A. V. (2019). Interhabitat variation in diplochory: Seed dispersal effectiveness by birds and ants differs 
between tropical forest and savanna. Perspectives in Plant Ecology, Evolution and Systematics, 38, 48-57. https://doi.org/10.1016/j. ppees.2019.04.002

Cazetta, E., Schaefer, H. M., \& Galetti, M. (2008). Does attraction to frugivores or defense against pathogens shape fruit pulp composition? Oecologia, 155, 277-286. https://doi.org/10.1007/s0044 2-007-0917-6

Christianini, A. V., \& Oliveira, P. S. (2010). Birds and ants provide complementary seed dispersal in a neotropical savanna. Journal of Ecology, 98, 573-582. https://doi.org/10.1111/j.1365-2745.2010.01653.x

Connell, J. H. (1971). On the role of natural enemies in preventing competitive exclusion in some marine animals and in rain forest trees. In P. J. Den Boer, \& G. Gradwell (Eds.), Dynamics of populations (1st ed., pp 298-312). Wageningen, The Netherlands: Centre for Agricultural Publishing and Documentation.

Craig, T. P., Itami, J. K., \& Horner, J. D. (2007). Geographic variation in the evolution and coevolution of a tritrophic interaction. Evolution, 61, 1137-1152. https://doi.org/10.1111/j.1558-5646.2007.00099.x

Fontúrbel, F. E., \& Medel, R. (2017). Frugivore-mediated selection in a habitat transformation scenario. Scientific Reports, 7, 1-10. https:// doi.org/10.1038/srep45371

García, D., Zamora, R., Gómez, J. M., \& Hódar, J. A. (1999). Bird rejection of unhealthy fruits reinforces the mutualism between juniper and its avian dispersers. Oikos, 85, 536-544. https://doi. org $/ 10.2307 / 3546703$

Giladi, I. (2006). Choosing benefits or partners: A review of the evidence for the evolution of myrmecochory. Oikos, 112, 481-492. https://doi. org/10.1111/j.0030-1299.2006.14258.x

Godfray, H. C. J. (1994). Parasitoids: Behavioural and evolutionary ecology. Princeton, NJ: Princeton University Press.

Gómez, C., \& Espadaler, X. (2013). An update of the world survey of myrmecochorous dispersal distances. Ecography, 36, 1193-1201. https:// doi.org/10.1111/j.1600-0587.2013.00289.x

Gómez, J. M. (2004). Bigger is not always better: Conflicting selective pressures on seed size in Quercus ilex. Evolution, 58, 71-80. https:// doi.org/10.1111/j.0014-3820.2004.tb01574.x

Goya, J. F., Placci, L. G., Arturi, M. F., \& Brown, A. (1992). Estructura y distribución de los talares de la reserva de biosfera Parque Costero del Sur. Revista De La Facultad De Agronomía De La Plata, 68, 53-64.

Grace, J. B. (2006). Structural equation modeling and natural systems. Cambridge, UK: Cambridge University Press.

Guerra, T. J., Dayrell, R. L., Arruda, A. J., Dáttilo, W., Teixido, A. L., Messeder, J. V., \& Silveira, F. A. (2017). Intraspecific variation in fruit-frugivore interactions: Effects of fruiting neighborhood and consequences for seed dispersal. Oecologia, 185, 233-243. https:// doi.org/10.1007/s00442-017-3943-z

Harrison, X. A., Donaldson, L., Correa-Cano, M. E., Evans, J., Fisher, D. N., Goodwin, C. E. D., ... Inger, R. (2018). A brief introduction to mixed effects modelling and multi-model inference in ecology. PeerJ, 6, e4794. https://doi.org/10.7717/peerj.4794

Harvey, J. A., Van Dam, N. M., \& Gols, R. (2003). Interactions over four trophic levels: Foodplant quality affects development of a hyperparasitoid as mediated through a herbivore and its primary parasitoid. Journal of Animal Ecology, 72, 520-531. https://doi. org/10.1046/j.1365-2656.2003.00722.x

Herrera, C. M. (1984). Selective pressures on fruit seediness: Differential predation of fly larvae on the fruits of Berberis hispanica. Oikos, 42, 166-170. https://doi.org/10.2307/3544789

Herrera, C. M. (1985). Determinants of plant-animal coevolution: The case of mutualistic dispersal of seeds by vertebrates. Oikos, 44, 132141. https://doi.org/10.2307/3544054

Jakobsson, A., \& Eriksson, O. (2000). A comparative study of seed number, seed size, seedling size and recruitment in grassland plants. Oikos, 88, 494-502. https://doi. org/10.1034/j.1600-0706.2000.880304.x
Janzen, D. H. (1970). Herbivores and the number of tree species in tropical forests. The American Naturalist, 104, 501-528. https://doi. org $/ 10.1086 / 282687$

Janzen, D. H. (1977). Why fruits rot, seeds mold, and meat spoils. The American Naturalist, 111, 691-713. https://doi.org/10.1086/283200

Jordano, P. (1987). Avian fruit removal: Effects of fruit variation, crop size, and insect damage. Ecology, 68, 1711-1723. https://doi. org/10.2307/1939863

Jordano, P. (1995). Frugivore-mediated selection on fruit and seed size: Birds and St. Lucie's cherry, Prunus mahaleb. Ecology, 76, 2627-2639. https://doi.org/10.2307/2265833

Jordano, P., \& Herrera, C. M. (1995). Shuffling the offspring: Uncoupling and spatial discordance of multiple stages in vertebrate seed dispersal. Ecoscience, 2, 230-237. https://doi.org/10.1080/11956 860.1995.11682288

Krebs, C. J. (1989). Ecological methodology. New York, NY: Harper \& Row. Lande, R., \& Arnold, S. J. (1983). The measurement of selection on correlated characters. Evolution, 37, 1210-1226. https://doi. org/10.1111/j.1558-5646.1983.tb00236.x

Lawton, J. H. (1999). Are there general laws in ecology? Oikos, 84, 177192. https://doi.org/10.2307/3546712

Lefcheck, J. S. (2016). piecewiseSEM: Piecewise structural equation modelling in $r$ for ecology, evolution, and systematics. Methods in Ecology and Evolution, 7, 573-579. https://doi.org/10.1111/2041-210X.12512

Levey, D. J. (1987). Seed size and fruit-handling techniques of avian frugivores. The American Naturalist, 129, 471-485. https://doi. org $/ 10.1086 / 284652$

Levey, D. J., \& Byrne, M. M. (1993). Complex ant-plant interactions: Rainforest ants as secondary dispersers and post-dispersal seed predators. Ecology, 74, 1802-1812. https://doi.org/10.2307/1939938

Loayza, A. P., \& Knight, T. (2010). Seed dispersal by pulp consumers, not "legitimate" seed dispersers, increases Guettarda viburnoides population growth. Ecology, 91, 2684-2695. https://doi. org/10.1890/09-0480.1

Manzaneda, A. J., Rey, P. J., \& Alcántara, J. M. (2009). Conflicting selection on diaspore traits limits the evolutionary potential of seed dispersal by ants. Journal of Evolutionary Biology, 22, 1407-1417. https:// doi.org/10.1111/j.1420-9101.2009.01752.x

Manzur, M. I., \& Courtney, S. P. (1984). Influence of insect damage in fruits of hawthorn on bird foraging and seed dispersal. Oikos, 43, 265-270. https://doi.org/10.1007/BF00317800

Martínez, I., García, D., \& Obeso, J. R. (2007). Allometric allocation in fruit and seed packaging conditions the conflict among selective pressures on seed size. Evolutionary Ecology, 21, 517-533. https:// doi.org/10.1007/s10682-006-9132-x

Mason, S. C., Sgarbi, C., Covachina, J. B. C., Peña, J. M., Berensztein, N. D., Margaría, C., \& Ricci, M. (2017). Acromyrmex Mayr (Hymenoptera: Formicidae: Myrmicinae): Patrones de distribución de las especies en la provincia de Buenos Aires, Argentina. Revista Del Museo Argentino De Ciencias Naturales Nueva Serie, 19, 185-199. https://doi. org/10.22179/REVMACN.19.483

Mehdiabadi, N. J., \& Schultz, T. R. (2010). Natural history and phylogeny of the fungus-farming ants (Hymenoptera: Formicidae: Myrmicinae: Attini). Myrmecological News, 13, 37-55.

Minor, D. M., \& Kobe, R. K. (2019). Fruit production is influenced by tree size and size-asymmetric crowding in a wet tropical forest. Ecology and Evolution, 9, 1458-1472. https://doi.org/10.1002/ece3.4867

Møller, A. P. (2008). Interactions between interactions: Predator-prey, parasite-host, and mutualistic interactions. Annals of the New York Academy of Sciences, 1133, 180-186. https://doi.org/10.1196/ annals.1438.007

Morales, J. M., García, D., Martínez, D., Rodriguez-Pérez, J., \& Herrera, J. M. (2013). Frugivore behavioural details matter for seed dispersal: A multi-species model for Cantabrian thrushes and trees. PLoS One, 8, e65216. https://doi.org/10.1371/journal.pone.0065216 
Morales, J. M., Rivarola, M. D., Amico, G., \& Carlo, T. A. (2012) Neighborhood effects on seed dispersal by frugivores: Testing theory with a mistletoe-marsupial system in Patagonia. Ecology, 93, 741-748. https://doi.org/10.1890/11-0935.1

Morrissey, M. B., \& Sakrejda, K. (2013). Unification of regression-based methods for the analysis of natural selection. Evolution, 67, 20942100. https://doi.org/10.1111/evo.12077

Murriello, S., Arturi, M., \& Brown, A. D. (1993). Fenología de las especies arbóreas de los talares del este de la Provincia de Buenos Aires. Ecología Austral, 3, 25-31.

Nakagawa, S., Johnson, P. C., \& Schielzeth, H. (2017). The coefficient of determination $\mathrm{R}^{2}$ and intra-class correlation coefficient from generalized linear mixed-effects models revisited and expanded. Journal of the Royal Society Interface, 14, 20170213. https://doi.org/10.1098/ rsif.2017.0213

Ness, J. H., Bronstein, J. L., Andersen, A. N., \& Holland, J. N. (2004) Ant body size predicts dispersal distance of ant-adapted seeds: Implications of small-ant invasions. Ecology, 85, 1244-1250. https:// doi.org/10.1890/03-0364

Norrbom, A. L. (1994). New species and phylogenetic analysis of Cryptodacus, Haywardina, and Rhagoletotrypeta (Diptera: Tephritidae). Insecta Mundi, 8, 37-65.

Nychka, D., Furrer, R., Paige, J., \& Sain, S. (2017). fields: Tools for spatial data. $R$ package version 9.6. Retrieved from www.image.ucar. edu/ nychka/Fields

Ohgushi, T., Schmitz, O., \& Holt, R. D. (2012). Trait-mediated Indirect Interactions: Ecological and evolutionary perspectives. Cambridge, UK: Cambridge University Press.

Oliveira, P. S., Galetti, M., Pedroni, F., \& Morellato, L. P. C. (1995). Seed cleaning by Mycocepurus goeldii ants (Attini) facilitates germination in Hymenaea courbaril (Caesalpiniaceae). Biotropica, 27, 518-522. https://doi.org/10.2307/2388966

Ortiz-Pulido, R., Albores-Barajas, Y. V., \& Díaz, S. A. (2007). Fruit removal efficiency and success: Influence of crop size in a neotropical treelet. Plant Ecology, 189, 147-154. https://doi.org/10.1007/s1125 8-006-9175-7

Ovruski, S. M., Norrbom, A. L., Schliserman, P., \& Aluja, M. (2005). Biology and taxonomy of Rhagoletotrypeta (Diptera: Tephritidae): A new species from Cuba and new host plant, parasitoid, and distribution records from Northwestern Argentina. Annals of the Entomological Society of America, 98, 252-258. https://doi.org/10.1603/0013-874 6(2005)098[0252:BATORD]2.0.CO;2

Palacio, F. X. (2016). Tree cover, patch structure and patch isolation correlate with patterns of Tufted Tit-Spinetail (Leptasthenura platensis) occurrence in Espinal forest remnants from east-central Argentina. Ornitología Neotropical, 27, 211-215.

Palacio, F. X., Girini, J. M., \& Ordano, M. (2017). Linking the hierarchical decision-making process of fruit choice and the phenotypic selection strength on fruit traits by birds. Journal of Plant Ecology, 10, 713-720. https://doi.org/10.1093/jpe/rtw063

Palacio, F. X., Lacoretz, M., \& Ordano, M. (2014). Bird-mediated selection on fruit display traits in Celtis ehrenbergiana (Cannabaceae). Evolutionary Ecology Research, 16, 51-62.

Palacio, F. X., Lacoretz, M. V., Pérez, E. C., \& Ordano, M. (2019). On a poorly known tritrophic interaction: Fruit-infesting Rhagoletotrypeta pastranai Aczél (Diptera: Tephritidae) and its parasitoid Utetes anastrephae (Viereck) (Hymenoptera: Braconidae) in Celtis ehrenbergiana (Klotzsch) Liebm. (Rosales: Cannabaceae) fruits. Revista De La Sociedad Entomológica Argentina, 78, 29-32. https://doi.org/10.25085/rsea.780306

Palacio, F. X., \& Ordano, M. (2018). The strength and drivers of bird-mediated selection on fruit crop size: A meta-analysis. Frontiers in Ecology and Evolution, 6, 18. https://doi.org/10.3389/ fevo.2018.00018

Palacio, F. X., Valoy, M., Bernacki, F., Sánchez, M. S., Núñez-Montellano, M. G., Varela, O., \& Ordano, M. (2017). Bird fruit consumption results from the interaction between fruit-handling behaviour and fruit crop size. Ethology Ecology and Evolution, 29, 24-37. https://doi. org/10.1080/03949370.2015.1080195

Penn, H. J., \& Crist, T. O. (2018). From dispersal to predation: A global synthesis of ant-seed interactions. Ecology and Evolution, 8, $9122-$ 9138. https://doi.org/10.1002/ece3.4377

Peters, M., Oberrath, R., \& Böhning-Gaese, K. (2003). Seed dispersal by ants: Are seed preferences influenced by foraging strategies or historical constraints? Flora - Morphology, Distribution, Functional Ecology of Plants, 198, 413-420. https://doi. org/10.1078/0367-2530-1210114

Phillips, P. C., \& Arnold, S. J. (1989). Visualizing multivariate selection. Evolution, 43, 1209-1222. https://doi.org/10.2307/2409357

Pinheiro, J., Bates, D., DebRoy, S., Sarkar, D.; R Core Team (2018). nlme: Linear and nonlinear mixed effects models. $R$ package version 3.1-137. Retrieved from https://CRAN.R-project.org/package=nlme

Poyet, M., Le Roux, V., Gibert, P., Meirland, A., Prévost, G., Eslin, P., \& Chabrerie, O. (2015). The wide potential trophic niche of the Asiatic fruit fly Drosophila suzukii: The key of its invasion success in temperate Europe? PLoS One, 10, e0142785. https://doi.org/10.1371/journ al.pone. 0142785

Primack, R. B., \& Kang, H. (1989). Measuring fitness and natural selection in wild plant populations. Annual Review of Ecology and Systematics, 20, 367-396. https://doi.org/10.1146/annurev.es.20.110189.002055

Prokopy, R. J. (1968). Visual responses of apple maggot flies, Rhagoletis pomonella (Diptera: Tephritidae): Orchard studies. Entomologia Experimentalis Et Applicata, 11, 403-422. https://doi. org/10.1111/j.1570-7458.1968.tb02070.x

Prokopy, R. J., Cooley, S. S., \& Papaj, D. R. (1993). How well can relative specialist Rhagoletis flies learn to discriminate fruit for oviposition? Journal of Insect Behavior, 6, 167-176. https://doi.org/10.1007/BF010 51502

R Core Team (2018). R: A language and environment for statistical computing. Version 3.5.2. Vienna, Austria: R Foundation for Statistical Computing. Retrieved from https://www.R-project.org/

Romanczuk, M. C., \& del Pero de Martínez, M. A. (1978). Las especies del género Celtis (Ulmaceae) en la flora argentina. Darwiniana, 21, 541-577.

Sargent, S. (1990). Neighborhood effects on fruit removal by birds: A field experiment with Viburnum dentatum (Caprifoliaceae). Ecology, 71, 1289-1298. https://doi.org/10.2307/1938266

Scheiner, S. M., Mitchell, R. J., \& Callahan, H. S. (2000). Using path analysis to measure natural selection. Journal of Evolutionary Biology, 13, 423-433. https://doi.org/10.1046/j.1420-9101.2000.00191.x

Schupp, E. W. (1993). Quantity, quality and the effectiveness of seed dispersal by animals. Vegetatio, 107, 15-29. https://doi.org/10.1007/ BF00052209

Shipley, B. (2009). Confirmatory path analysis in a generalized multilevel context. Ecology, 90, 363-368. https://doi. org/10.1890/08-1034.1

Shipley, B. (2013). The AIC model selection method applied to path analytic models compared using ad-separation test. Ecology, 94, 560564. https://doi.org/10.1890/12-0976.1

Siepielski, A. M., \& Benkman, C. W. (2004). Interactions among moths, crossbills, squirrels, and lodgepole pine in a geographic selection mosaic. Evolution, 58, 95-101. https://doi. org/10.1111/j.0014-3820.2004.tb01576.x

Siepielski, A. M., \& Benkman, C. W. (2007a). Selection by a predispersal seed predator constrains the evolution of avian seed dispersal in pines. Functional Ecology, 21, 611-618. https://doi. org/10.1111/j.1365-2435.2007.01261.x

Siepielski, A. M., \& Benkman, C. W. (2007b). Extreme environmental variation sharpens selection that drives the evolution of a mutualism. Proceedings of the Royal Society B: Biological Sciences, 274, 17991805. https://doi.org/10.1098/rspb.2007.0449 
Siepielski, A. M., \& Benkman, C. W. (2008a). Seed predation and selection exerted by a seed predator influence subalpine tree densities. Ecology, 89, 2960-2966. https://doi.org/10.1890/08-0072.1

Siepielski, A. M., \& Benkman, C. W. (2008b). A seed predator drives the evolution of a seed dispersal mutualism. Proceedings of the Royal Society B: Biological Sciences, 275, 1917-1925. https://doi. org/10.1098/rspb.2008.0451

Siepielski, A. M., \& Benkman, C. W. (2010). Conflicting selection from an antagonist and a mutualist enhances phenotypic variation in a plant. Evolution, 64, 1120-1128. https://doi. org/10.1111/j.1558-5646.2009.00867.x

Singer, M. S., Farkas, T. E., Skorik, C. M., \& Mooney, K. A. (2012). Tritrophic interactions at a community level: Effects of host plant species quality on bird predation of caterpillars. American Naturalist, 179, 363-374. https://doi.org/10.1086/664080

Sivinski, J., Aluja, M., \& López, M. (1997). Spatial and temporal distributions of parasitoids of Mexican Anastrepha species (Diptera: Tephritidae) within the canopies of fruit trees. Annals of the Entomological Society of America, 90, 604-618. https://doi.org/10.1093/aesa/90.5.604

Sobral, M., Guitián, J., Guitián, P., \& Larrinaga, A. R. (2013). Selective pressure along a latitudinal gradient affects subindividual variation in plants. PLoS One, 8, e74356. https://doi.org/10.1371/journ al.pone. 0074356

Sobral, M., Larrinaga, A. R., \& Guitián, J. (2010). Do seed-dispersing birds exert selection on optimal plant trait combinations? Correlated phenotypic selection on the fruit and seed size of hawthorn (Crataegus monogyna). Evolutionary Ecology, 24, 1277-1290. https://doi. org/10.1007/s10682-010-9380-7

Start, D., Weis, A. E., \& Gilbert, B. (2019). Indirect interactions shape selection in a multispecies food web. The American Naturalist, 193, 321-330. https://doi.org/10.1086/701785

Strauss, S. Y., \& Irwin, R. E. (2004). Ecological and evolutionary consequences of multispecies plant-animal interactions. Annual Review of Ecology, Evolution and Systematics, 35, 435-466. https://doi. org/10.1146/annurev.ecolsys.35.112202.130215

Strauss, S. Y., Sahli, H., \& Conner, J. K. (2005). Toward a more trait-centered approach to diffuse (co) evolution. New Phytologist, 165, 81-90. https://doi.org/10.1146/10.1111/j.1469-8137.2004.01228.x

TerHorst, C. P., Lau, J. A., Cooper, I. A., Keller, K. R., Rosa, R. J. L., Royer, A. M., ... Conner, J. K. (2015). Quantifying nonadditive selection caused by indirect ecological effects. Ecology, 96, 2360-2369. https://doi. org/10.1002/ecy.1744

Tewksbury, J. J. (2002). Fruits, frugivores and the evolutionary arms race. New Phytologist, 156, 137-139. https://doi. org/10.1046/j.1469-8137.2002.00522.x

Thompson, J. N. (1999). The evolution of species interactions. Science, 284, 2116-2118. https://doi.org/10.1126/science.284.5423.2116

Thompson, J. N. (2009). The coevolving web of life (American society of naturalists presidential address). The American Naturalist, 173, 125140. https://doi.org/10.1086/595752

Torretta, J. P., \& Basilio, A. M. (2009). Dispersión polínica y éxito reproductivo de cuatro especies arbóreas de un bosque xerófito de Argentina. Revista De Biología Tropical, 57, 283-292. https://doi. org/10.15517/rbt.v57i1-2.11321

Traveset, A., Willson, M. F., \& Gaither, J. C. Jr (1995). Avoidance by birds of insect-infested fruits of Vaccinium. Oikos, 73, 381-386. https://doi. org/10.2307/3545962

Tscharntke, T. (1992). Cascade effects among four trophic levels: Bird predation on galls affects density-dependent parasitism. Ecology, 73, 1689-1698. https://doi.org/10.2307/1940020
Valburg, L. K. (1992). Eating infested fruits: Interactions in a plant-disperser-pest triad. Oikos, 65, 25-28. https://doi.org/10.2307/3544883

Van Dam, N. M. (2009). How plants cope with biotic interactions. Plant Biology, 11, 1-5. https://doi.org/10.1111/j.1438-8677.2008.00179.x

Vander Wall, S. B., \& Longland, W. S. (2004). Diplochory: Are two seed dispersers better than one? Trends in Ecology and Evolution, 19, 155161. https://doi.org/10.1016/j.tree.2003.12.004

Varela, O., Cormenzana-Méndez, A., Krapovickas, L., \& Bucher, E. H. (2008). Seasonal diet of the Pampas fox (Lycalopex gymnocercus) in the Chaco dry woodland, northwestern Argentina. Journal of Mammalogy, 89, 1012-1019. https://doi.org/10.1644/07-MAMM-A-125.1

Varela, R. O., \& Perera, T. C. (2003). Dispersal of Schinus fasciculatus seeds by the leaf-cutting ant Acromyrmex striatus in a shrubland of the dry Chaco, Argentina. Journal of Tropical Ecology, 19, 91-94. https://doi.org/10.1017/S0266467403003109

Wajnberg, E., Bernstein, C., \& Van Alphen, J. (2008). Behavioral ecology of insect parasitoids: From theoretical approaches to field applications. Oxford, UK: Blackwell Publishing.

Walsh, M. R. (2013). The evolutionary consequences of indirect effects. Trends in Ecology and Evolution, 28, 23-29. https://doi.org/10.1016/j. tree.2012.08.006

Wang, B. C., \& Smith, T. B. (2002). Closing the seed dispersal loop. Trends in Ecology \& Evolution, 17, 379-386. https://doi.org/10.1016/S0169 $-5347(02) 02541-7$

Wharton, R. A., \& Marsh, P. M. (1978). New world opiinae (hymenoptera: Braconidae) parasitic on tephritidae (diptera). Journal of the Washington Academy of Sciences, 68, 147-167.

Wheelwright, N. T., \& Orians, G. H. (1982). Seed dispersal by animals: Contrasts with pollen dispersal, problems of terminology, and constraints on coevolution. The American Naturalist, 119, 402-413. https://doi.org/10.1086/283918

Whitney, K. D., \& Stanton, M. L. (2004). Insect seed predators as novel agents of selection on fruit color. Ecology, 85, 2153-2160. https:// doi.org/10.1890/03-3138

Wickham, H. (2016). ggplot2: Elegant graphics for data analysis. New York, NY: Springer.

Wood, C. W., \& Brodie, E. D. (2016). Natural selection, measuring. In R. M. Kliman (Ed.), Encyclopedia of evolutionary biology (1st ed., pp. 104111). Oxford, UK: Academic Press.

Wood, S. N. (2017). Generalized additive models: An introduction with R. Boca Raton, FL: Chapman \& Hall/CRC.

Wulff, R. D. (1986). Seed size variation in Desmodium paniculatum: I. Factors affecting seed size. Journal of Ecology, 74, 87-97. https://doi. org/10.2307/2260351

\section{SUPPORTING INFORMATION}

Additional supporting information may be found online in the Supporting Information section.

How to cite this article: Palacio FX, Siepielski AM, Lacoretz MV, Ordano M. Selection on fruit traits is mediated by the interplay between frugivorous birds, fruit flies, parasitoid wasps and seed-dispersing ants. J Evol Biol. 2020;33:874886. https://doi.org/10.1111/jeb.13656 